\title{
Optical radiation in modern medicine
}

\author{
Paweł Sowa', Joanna Rutkowska-Talipska ${ }^{2}$, Krzysztof Rutkowski ${ }^{3}$, Bożena Kosztyła-Hojna ${ }^{4}$, Ryszard Rutkowski
}

1Department of Public Health, Medical University of Bialystok, Poland

Head: Prof. Andrzej Szpak MD, PhD

2Department of Rehabilitation, Medical University of Bialystok, Poland

Head: Prof. Anna Kuryliszyn-Moskal MD, PhD

${ }^{3}$ Department of Allergy, Cambridge University Hospital, Cambridge, United Kingdom

Head: Dr P.W. Ewan FRCP, FRCPath

${ }^{4}$ Department of Clinical Phonoaudiology and Speech Therapy, Medical University of Bialystok, Poland

Head: Prof. Bożena Kosztyła-Hojna MD, PhD

${ }^{5}$ Department of Respiratory Diagnostics and Bronchoscopy, Medical University of Bialystok, Poland

Head: Prof. Zenon Siergiejko MD, PhD

Postep Derm Alergol 2013; XXX, 4: 246-251

DOI: $10.5114 /$ pdia.2013.37035

\begin{abstract}
Optical radiation extends between microwaves and X-rays of the electromagnetic radiation and includes ultraviolet (UV), visible light (VL) and infrared (IR) components. The dose of radiation that reaches the skin is influenced by the ozone layer, position of the Sun, latitude, altitude, cloud cover and ground reflections. The photobiological effects of UV, VL and IR bands depend on their wavelength, frequency and mechanism of action. They are modified by the thickness, structure, vasculature and pigmentation of skin's stratum corneum, epidermis and dermis. Following absorption, IR affects the body mainly through transfer of thermal energy to tissues. Visible light and skin interact either thermally or photochemically, whereas UV acts mainly photochemically. Optical radiation in the form of sunlight therapy had been used already in ancient times. Nowadays IR, VL and UV are widely applied in the therapy of allergic, dermatological, cardiovascular, respiratory, rheumatic, neonatal, pediatric and psychiatric disorders.
\end{abstract}

Key words: infrared, medicine, optical, radiation, ultraviolet, visible.

\section{Introduction}

Natural optical radiation had been used in ancient China, India, Egypt, Greece and Rome for heliotherapy and phototherapy. During the Middle Ages, heliotherapy was forgotten in Europe. A widespread interest in the therapeutic properties of solar radiation re-emerged only in the second half of the nineteenth century. In 1855, Arnold Rikli opened a thermal station for heliotherapy in Veldes (Bled), Slovenia. In 1894, Lahmann (Germany) constructed and used for the first time an artificial light source to treat skin disorders. Niels Ryberg Fiensen, the 1903 Nobel Prize winner, laid the foundations for modern helio- and phototherapy used to treat smallpox, lupus vulgaris and tuberculosis of the skin, bone and joints. A widespread use of phototherapy using artificial optical radiation became possible in 1912, when Ernst Kromayer (Berlin) designed a quartz lamp with a strong ultraviolet emission [1-3]. More recently, optical radiation has been commonly used to treat allergic, cardio- vascular, dermatological, neonatal, paediatric, psychiatric, respiratory and rheumatoid disorders [4-13]. Heliotherapy, heliothalassotherapy (climatotherapy with simultaneous spa therapy at a costal sea, especially the Dead Sea), photo-, photochemo- , balneophoto- and far infrared heat therapy have also gained prominence [3, 6, 10-14].

\section{Ultraviolet, visible light and infrared radiation}

The Sun is a natural source of optical radiation. New artificial sources used for phototherapeutic, cosmetic or lifestyle purposes are constantly gaining importance [5, 1517]. Optical radiation is essentially nonionising and extends between microwaves and X-rays of the electromagnetic spectrum. It includes ultraviolet (UV), visible (VL) and infrared (IR) components (Table 1) [17-21].

The ozone layer, position of the Sun, latitude, altitude, cloud cover and ground reflection influence the dose of optical radiation that reaches the skin. UVC below $290 \mathrm{~nm}$ and

Address for correspondence: Prof. Ryszard Rutkowski MD, PhD, 20 m.6 Starobojarska St, 15-073 Bialystok, Poland, phone: +48 608255 565, e-mail: rutkowski@csk.pl

Received: 28.11.2012, accepted: 21.04.2013. 
IRC of wavelength over $30000 \mathrm{~nm}$ are completely ab-sorbed by stratospheric gases (10-50 km above sea level), mainly ozone $\left(\mathrm{O}_{3}\right)$, dioxygen $\left(\mathrm{O}_{2}\right)$ and water vapour $\left(\mathrm{H}_{2} \mathrm{O}\right)$. The risk of harmful irradiation with UVC or with very long IRC has significantly increased in recent years due to the decreasing thickness of the ozone layer over the southern hemisphere, mainly over the Antarctic. More than $90 \%$ of UVB is absorbed by $\mathrm{O}_{3}$. Ultraviolet A passes through the atmosphere unchanged and makes up about $95 \%$ of total UV at Earth's surface, whereas UVB only 5\%. Infrared radiation and $V L$ predominate in the morning. UVB and UVA become dominant around noon. About $20-30 \%$ of total daily UV radiation is received $1 \mathrm{~h}$ either side of midday in summer, with 75\% between 9 am and 3 pm [3, 5, 18, 20-22].

UV radiation (UVR) increases with altitude as the number of scattering and absorbing air molecules and aerosols in atmosphere decrease. In general, each $1 \mathrm{~km}$ increase in altitude increases ultraviolet flux by about $6 \%$. Because of this, places like the Dead Sea, which is below sea level, are relatively poorer in UVB than nearby sites at sea level. Solar altitude depends on the time of day, day of year, and geographical location (latitude and longitude). Annual UVR flux decreases with the distance from the Equator.

In the troposphere (0 to $10 \mathrm{~km}$ above sea level) absorption by the pollutants (ozone, nitrogen dioxide $\left(\mathrm{NO}_{2}\right)$, sulphur dioxide $\left(\mathrm{SO}_{2}\right)$ ) and scattering by particulates and clouds are the main attenuating processes. Clouds and fog reduce optical irradiance at the Earth's surface although changes in the UV region are not as great as those of total intensity, since water in clouds and fog attenuates solar IR much more than UV. Reflection of UVR from ground surfaces is normally less than $10 \%$ with the exception of gypsum sand, which reflects 15-30\%, and snow, which can reflect up to $90 \%$. Calm waters reflect only about $5 \%$ of incident UVR; up to $20 \%$ is reflected from choppy water. Because UV rays pass easily through water, swimming in either the sea or open-air pools offers little protection against sunburn [3-5, 17, 22-24].

\section{The human skin optic}

The photobiological effects of UV, VL and IR depend on their wavelength, frequency, mechanism of action and are modified by the thickness, structure, vasculature and pigmentation of skin's stratum corneum, epidermis and dermis (Figure 1) [19, 25-29].

Stratum corneum (horny cell layer) is the exterior sublayer of the epidermis composed of several layers of dry, dead, hexagonal, flat and filled with keratin horny cells (corneocytes). It contains 10-15\% of water in the epidermis hence effectively absorbing IR.

The epidermis is the outer layer of skin, largely composed of connective tissue, melanocytes and keratinocytes produced in stratum basale. There are no veins and capillaries in this layer. The epidermis is further divided into stratum lucidum (clear layer; only in soles and palms), stratum granulosum (granular layer), stratum spinosum (spinous lay-
Table 1. Optical spectrum [15, 18-20, 23, 39, 60]

\begin{tabular}{|c|c|}
\hline Radiation type & Wavelength \\
\hline \multicolumn{2}{|l|}{$42-45 \%$ of solar spectrum } \\
\hline IRA $\left(\right.$ near $\left.^{\star}\right)$ & $760-1400 \mathrm{~nm}$ \\
\hline IRB (mid or middle) & $1400-3000 \mathrm{~nm}$ \\
\hline IRC (far or long) & $3000 \mathrm{~nm}-1 \mathrm{~mm}$ \\
\hline Visible (light) & $380-780 \mathrm{~nm}$ \\
\hline \multicolumn{2}{|l|}{$50-52 \%$ of solar spectrum } \\
\hline Red & $625-780 \mathrm{~nm}$ \\
\hline Orange & $590-625 \mathrm{~nm}$ \\
\hline Yellow & $565-590 \mathrm{~nm}$ \\
\hline Green & $500-565 \mathrm{~nm}$ \\
\hline Blue & $435-500 \mathrm{~nm}$ \\
\hline Violet & $380-435 \mathrm{~nm}$ \\
\hline \multicolumn{2}{|l|}{$5-6 \%$ of solar spectrum } \\
\hline UVA & $315-400 \mathrm{~nm}$ \\
\hline UVA1 & $340-400 \mathrm{~nm}$ \\
\hline UVA2 & $320-340 \mathrm{~nm}$ \\
\hline UVB & $280-315 \mathrm{~nm}$ \\
\hline UVC & $100-280 \mathrm{~nm}$ \\
\hline
\end{tabular}

$\mathrm{nm}$ - nanometre, $\mathrm{mm}$ - millimetre, * previous classification

er) and stratum basale (basal layer). Stratum basale is the deepest sublayer of the epidermis which forms the boundary to the dermis. An effective photoprotective system relies on the epidermal hyperplasia, melanogenesis and perhaps urocainic acid synthesis. The dermis is much thicker than the epidermis, which mainly propagates and absorbs optical radiation. It is divided into papillary and reticular region primarily composed of a dense, irregular connective tissue with nerves and blood vessels. There are fewer cells and more fibers in the dermis compared to the epidermis. Collagen and elastin fibers are the main components of the dermis. The subcutaneous tissue, hypodermis, is a subcutaneous adipose tissue characterized by a negligible absorption of light in the visible region of the spectrum. The hypodermis contains $50 \%$ of body fat. Due to the presence of white fat deposits, most of the visible light that reaches this tissue is reflected back to the upper layers [25-29].

Ninety-three-ninety-six percent of incident radiation which is not reflected from skin's outer surface is scattered in stratum corneum, epidermis and dermis and then absorbed by skin biomolecules (chromophores or photosensitisers). Scattering is greater in the red spectrum and increases progressively towards the infrared section of the spectrum. It influences the depth of photonic penetration into the epidermis and dermis which initiates acute and chronic response in the skin [5, 19, 20, 25, 27, 30-32].

Lipids and proteins embedded in the fluids in and between skin cells are the main scattering particles. Lipid scatterers are found in stratum corneum, cell membranes and intracellular particles. Keratins and melanins in the epidermis and collagen and elastin fibers in the dermis are the protein scatterers $[25,29,30]$. The amount of UV, VL or IR absorbed 


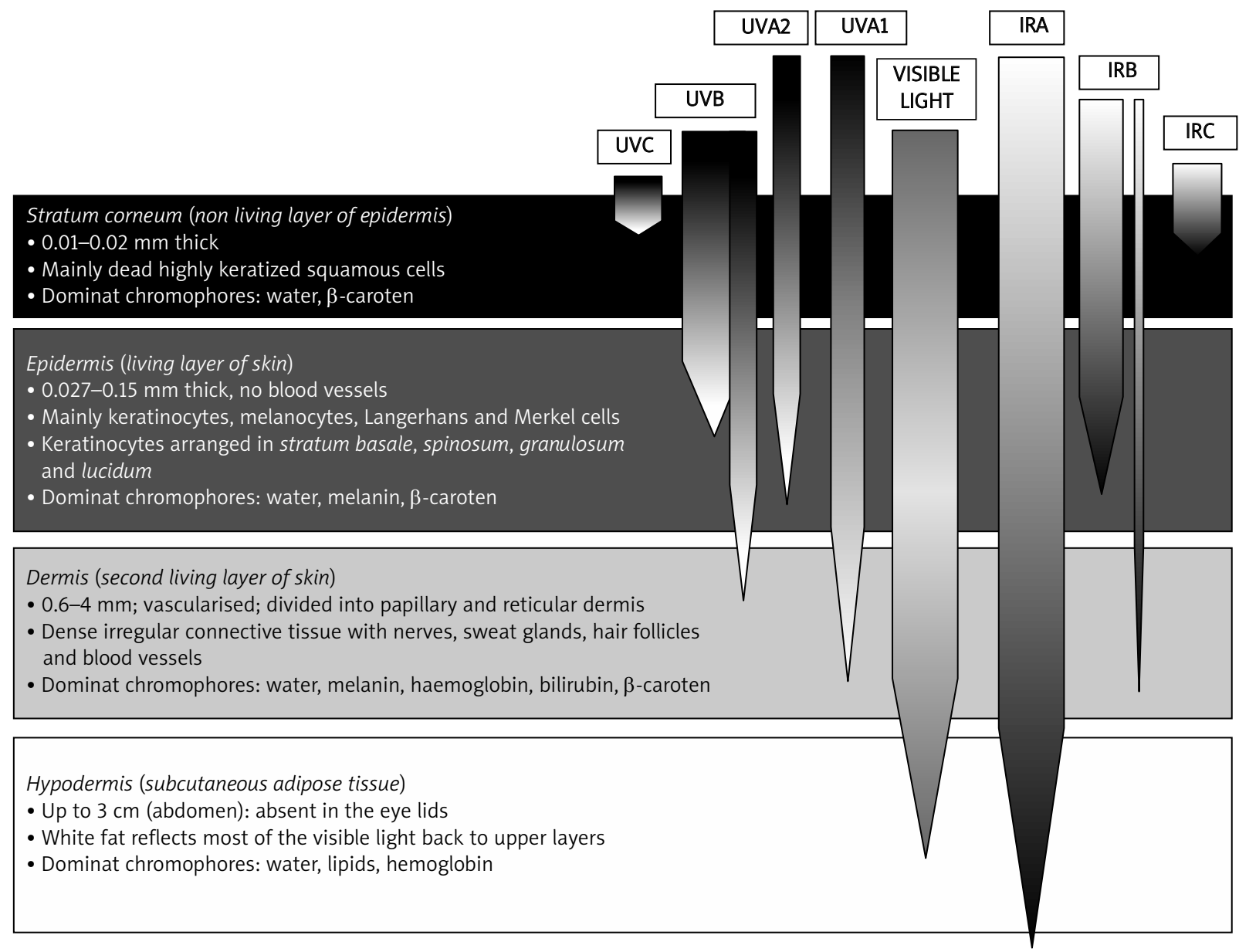

Figure 1. Penetration of optical radiation into skin $[5,16,24,26,27,39]$

by chromophores strictly depends on the chemical structure and number of these molecules. The wavelengths that are absorbed with the highest probability are called absorption maxima $[5,6,20,27,30,33]$. Solar radiation is absorbed by endogenous nucleic acids, aromatic amino acids, urocainic acid, tryptophan, tyrosine, NADPH, NADH cofactors, cytochromes, riboflavins, porphyrins, melanin and melanin precursors, protoporphyrin IX, bilirubin, haemoglobin, $\beta$-carotene or water molecules [5, 6, 20, 26, 27, 30, 31, 33]. Some of them absorb UVB only, some both UVB and UVA and others UVB and visible wavebands but the majority absorb more than one spectral range [30, 32, 33].

Numerous skin biomolecules act as absorbents mainly within the UVB range. These are nucleic acids, aromatic amino acids, NADH and NADPH, heme, quinones, flavins, porphyrins, carotenoids, 7-dehydrocholesterol, eumelanin and urocanic acid (UCA) [20, 25, 30].

$\beta$-Carotene that has two absorption maxima at about $465 \mathrm{~nm}$ and $490 \mathrm{~nm}$ in the visible light and UV region, respectively. Protoporphyrin IX with an absorption maximum at about $405 \mathrm{~nm}$ strongly absorbs UVA. Melanin absorbs throughout the UVB, UVA and visible wavebands without an absorption maximum. The absorption property of epidermis comes mostly from melanin. Oth- er chromophores like bilirubin, haemoglobin and riboflavin absorb mainly VL. In the UV region, less than $300 \mathrm{~nm}$ aromatic amino acids, nucleic acids, urocainic acid and melanin are the major epidermal absorbers. Infrared radiation is absorbed mainly by water molecules. Absorption of the water and haemoglobin in the dermis and melanin and lipids in the epidermis define the absorption of the whole skin $[20,25,30]$.

\section{Ultraviolet, visible light and infrared radiation in the skin}

Stratum corneum and epidermis provide an optical barrier primarily by absorption of radiation and to a lesser degree by optical scattering. The dermis largely defines the depth of optical penetration. Optical radiation with a higher energy and shorter wavelength is less penetrating than longer wavelengths. It therefore does not affect the deeper skin layers to the same degree. Infrared radiation waves penetrate into the skin deeper than shorter VL and UVR reaching even the subcutaneous adipose tissue (Figure 1) [4, 24-27, 30].

Infrared radiation with waves near $4000 \mathrm{~nm}$ behave like microwaves and penetrate up to a depth of several 
centimetres. Far IRC is strongly absorbed by water particles on the skin surface so penetrates only into stratum cor-neum, at a depth of $0.1 \mathrm{~mm}$. In stratum corneum IRC radiation does not exceed beyond the uppermost layer of the dead skin cells and does not reach the blood vessels. Infrared radiation B penetrates mainly the epidermis but partially passes through the dermis at a depth of $1.5 \mathrm{~mm}$. The shortest IRA rays penetrate approximately $3 \mathrm{~mm}$ deep into the skin to the subcutaneous layer [15, $27,30,34]$

Infrared radiation A penetrates into the skin deeper than VL and UVR. Visible light operates much more superficially than IR and is highly absorbed by haemoglobin of the vascular layer of the skin and melanin, located mainly within the epidermis. In the range of the blue colour of visible light the penetration depth reaches only $0.07 \mathrm{~mm}$. Ultraviolet $A$ rays are absorbed by the epidermis but $25-50 \%$ of solar UVA reaches melanocytes in the dermis. Ultraviolet $B$ beams reach mainly basal layer cells of the epidermis, and only a small part of UVB is absorbed by the dermal proteins, lipids and DNA (Figure 1) [5, 16, 24, 26, 27]

Following absorption of the radiant energy, the interaction with tissues is either thermal or photochemical. Infrared radiation act mainly thermally. Visible light and skin tissue interact thermally or photochemically. Ultraviolet radiation with the highest photon energy act mainly photochemically. Infrared radiation influences the UV-induced photochemical reactions and enhances the damaging effect of UV on human skin $[4,16,17,22,24$, $25,27,30,32,34,35]$.

\section{Biological effects and medical application of infrared radiation}

Infrared radiation affects the body through the transfer of its thermal energy to tissues or by a direct heat production from an increased movement of the molecules in affected organs. When IRA reaches the eye, the radiation is absorbed by the iris and converted into heat which is then conducted to the lens. It may cause cataracts. Infrared radiation $B$ and IRC is converted into heat in the cornea and induces cataracts in the lens indirectly. Human skin exposed to a high level of IR gets warm, painful and may burn. Far IRC raises the skin temperature causing a thermal sensation ranging from pleasant warmth to thermal burns. Short-length IRA reaches the subcutaneous tissue without markedly increasing the surface temperature but induces heat-dependent changes in the cells and extracellular matrix of the dermis. It stimulates expression of metalloproteinases MMP-1, MMP-3 and MMP-12; regulates synthesis of elastin and fibrillin; affects formation of elastic fibres; controls production of TGF- $\beta$, IL- 6 and IL- 12 and causes neoangiogenesis contributing to solar elastosis and premature skin photoaging. Chronic, repeated exposure to submaximal heat with IR insufficient to produce burns induces pigmentary changes referred to as erythema $a b$ igne. Indirect effects of IR range from whole-body heat stress (hyperthermia) to cellular injury, where elevated cell temperatures can damage DNA [15, 16, 21, 36-40].

Cellular and molecular actions of IR in human skin have been discussed in many comprehensive reviews [16, 17, 21, 37, 38, 40, 41].

In 1989, a new form of thermal therapy for heart failure was introduced in Japan. It is based on a dry far-infrared sauna with temperature uniformly maintained at $60^{\circ} \mathrm{C}$. In 2007, it was named Waon therapy where "Wa" means so-othing, and "On" means warmth, hence Waon or "soothing warmth" infers warmth that comfortably refreshes the mind and body. Waon therapy utilizes IR warming cabins (infrared saunas), relatively new types of IR heating appliances. Infrared radiation C is frequently the main spectral emission encountered in infrared warming cabins, but there are also types which peak in the IR-A or IR-B wavelength range [15, 36, 42, 43]. Waon therapy is an innovative and highly promising strategy for treating chronic heart failure, chronic fatigue syndrome, depression, anxiety, fibromyalgia, rheumatoid arthritis, ankylosing spondylitis and severe chronic obstructive pulmonary disease [12, 42-47].

Infrared radiation is also widely used to measure and monitor skin temperature, arterial or regional tissue oxygen saturation, chest wall volume, neuronal brain activity, temperature-map target tissues and locate breast and brain tumours [27, 48-53]. It exerts a beneficial effect on skin texture and wrinkles by stimulating fibroblasts and increasing collagen and elastin content. Infrared radiation skin therapy may be an effective and safe non-ablative remodelling method useful in the treatment of photoaged skin and wounds [17, 37].

\section{Biological effects and medical application of visible light and ultraviolet radiation}

Visible light and infrared radiation A and B induce not only vitamin D synthesis and protective skin tan, but also skin erythema, accelerated photoaging and malignant transformation of the skin cells. Visible light and infrared radiation $A$ induce darkening of the pigment within a few hours by acting on the pre-existing melanin. They can also cause a persistent darkening of the skin. Erythema and delayed tan that develop days of UV exposure and sunburn are caused mainly by UVB which is 1000 times more erythematogenic than UVA. Infrared radiation $A$ and $V L$ also cause skin erythema, but at doses much higher than UVB [3, 6, 10, 24, 30, 32, 33, 39, 41, 54].

In a sensitive individual, natural or artificial UV and VL may trigger uneven activity of skin melanocytes which clinically manifests as lentigo simplex, lentigo maligna, vitiligo or stellate pseudoscars. Chronic UV and VL exposure may induce undesirable changes in the thickness of the epidermis with cutis rhomboidalis nuchae (sailor's or farmer's neck), thinning of the skin on forearms and the 
back of the hands. Ultraviolet radiation and VL are responsible for abnormal keratinisation with subsequent yellowish skin tone, actinic (senile) keratosis and cutaneous horns. Similarly to IRA, chronic UV and VL exposure may produce collagen and colloid degeneration, colloid milium, accumulation of abnormal collagen fibres, skin elastosis which significantly accelerate premature photoaging. Excessive UVB, UVA and VL light radiation are responsible for carcinogenesis in the skin and ocular adverse effects like photokeratitis (snow blindness), retinal burns, retinopathy and cataracts $[4,5,16,18,31,39,40]$.

Ultraviolet radiation A causes indirect DNA damage via reactive oxygen species. Ultraviolet radiation $B$ damages DNA directly and suppresses the immune system both locally and systemically. Such immunosuppression involves a complex relationship between antigen presenting cells, regulatory $T$ lymphocytes and released immunosuppressive cytokines and certainly contributes to photocarcinogenesis. A variety of therapeutic effects of UVA and UVB are due to their immunosuppressive effects. Ultraviolet radiation induces also a strong inflammatory response in susceptible individuals but its immunosuppressive effects predominate $[6,10,18,24,31,35,41,54-56]$. The molecular mechanism of UV-induced immunosuppression and other biological effects have been reviewed recently $[4,5$, 16-18, 30, 31, 41, 54, 55, 57].

Visible light is used to treat neonatal jaundice (hyperbilirubinemia), exacerbations of atopic dermatitis and acne vulgaris, seasonal affective disorders and depression. It allows for visualization of subsurface biological structures, including veins and arteries in the foot, hands or wrists of neonates for injections, venepuncture and cannulation. Visible light is also an integrated part of intense pulsed light therapy, low-level light therapy, and photodynamic therapy presently used for the treatment of many dermatoses $[1,3-6,14,36,58,59]$.

UVB phototherapy is a vital therapeutic option in skin diseases, particularly psoriasis and atopic dermatitis (AD). Broadband UVB $(280-320 \mathrm{~nm})$ is particularly effective in combination with local or systemic medications: corticosteroids, tars, calcipotriol, retinoids, methotrexate and emollients. The clinical effect of narrowband UVB (NBUVB; $311-313 \mathrm{~nm}$ ) phototherapy is improved when it is combined with retinoids, psoralens and vitamin D analogues. It is less erythematogenic due to the exclusion of short wavelength UVB. Combination UVA/B phototherapy used to be preferred in $A D$ before introduction of NB UVB and UVA1 therapy. Pure UVA1 (340-400 nm) plays a minor therapeutic role. The efficacy of UVA-1 phototherapy in AD, systemic sclerosis, chronic sclerodermoid, graft-versus-host disease, urticaria pigmentosa, cutaneous T-cell lymphoma and psoriasis in HIV-positive patients has been confirmed in several studies. Psoralen plus UVA (PUVA) therapy is the treatment of choice for different inflammatory and neoplastic skin diseases e.g. psoriasis vulgaris (effective in $90 \%$ of patients) $[10,11,24,35,60-62]$.

\section{Conclusions}

Electromagnetic radiation, including $I R, V L$ and $U V$ is essential in modern medicine. Undoubtedly, it is going to play an ever increasing role in physiotherapy and dermatology and remain of particular medical and scientific interest. As our understanding of the molecular mechanisms of IR action in the human body increases, new, safe and more effective therapeutic methods based on the visible and invisible electromagnetic radiation will be developed.

\section{References}

1. Bloch H. Solartheology, heliotherapy, phototherapy, and biologic effects: a historical overview. J Natl Med Assoc 1990; 82: $517-21$

2. Roelandts R. The history of phototherapy: something new under the sun? I Am Acad Dermatol 2002; 46: 926-30.

3. Wharton JR, Cockerell CJ. The sun: a friend and enemy. Clin Dermatol 1998; 16: 415-9.

4. Bowszyc-Dmochowska M. Phototherapy in dermatology. Przew Lek 2006; 7: 85-1.

5. Juzeniene A, Brekke P, Dahlback A, et al. Solar radiation and human health. Rep Prog Phys 2011; 74: 1-56.

6. Mahmoud BH, Hexsel CL, Hamzavi IH, Lim HW. Effects of visible light on the skin. Photochem Photobiol 2008; 84: 450-62.

7. Osmola-Mańkowska A, Silny W, Dańczak-Pazdrowska A, et al. A case of a Comél-Netherton syndrome patient treated with UVA1 phototherapy. Postep Derm Alergol 2011; 28: 41821.

8. Olek-Hrab K, Osmola-Mańkowska A, Silny W, et al. Use of UVA1 in the treatment of mycosis fungoides - case report. Postep Derm Alergol 2011; 28: 158-64.

9. Wojewoda K, Brenner J, Sokołowska-Wojdyło M, BarańskaRybak W. Treatment of primary cutaneous lymphoma with reference to the latest therapeutic consensus of the Polish Lymphoma Research Group (PLRG). Postep Derm Alergol 2012; 29: 63-8.

10. Malinowska K. UVA1 phototherapy in dermatological treatment. Postep Derm Alergol 2011; 28: 53-8.

11. Morison WL. Phototherapy and photochemotherapy: an update. Semin Cutan Med Surg 1999; 18: 297-06.

12. Tanaka Y, Akiyoshi J, Kawahara Y, et al. Infrared radiation has potential antidepressant and anxiolytic effects in animal model of depression and anxiety. Brain Stimul 2011; 4: 71-6.

13. Umehara M, Yamaguchi A, Itakura S, et al. Repeated waon therapy improves pulmonary hypertension during exercise in patients with severe chronic obstructive pulmonary disease. J Cardiol 2008; 51: 106-13.

14. Gambichler T. Management of atopic dermatitis using photo(chemo)therapy. Arch Dermatol Res 2009; 301: 197-203.

15. ICNIRP statement on far infrared radiation exposure. The International Commission on Non-Ionizing Radiation Protection. Health Physic 2006; 91: 630-45.

16. Schieke SM, Schroeder P, Krutmann J. Cutaneous effects of infrared radiation: from clinical observations to molecular response mechanisms. Photodermatol Photoimmunol Photomed 2003; 19: 228-34.

17. Schroeder P, Krutmann J. Infrared A radiation effects on the skin. Piel (Barc., Ed. impr.). 2011. doi:10.1016/j.piel.2011.01.012.

18. Ichihashi M, Ando H, Yoshida M, et al. Photoaging of the skin. Ani-Aging Med 2009; 6: 46-59. 
19. Sowa P, Rutkowska-Talipska J, Sulkowska U, et al. Electromagnetic radiation in modern medicine: physical and biophysical properties. Pol Ann Med 2012; 19: 139-42.

20. Svobodova A, Walterova D, Vostalova J. Ultraviolet light induced alteration to the skin. Biomed Pap Med Fac Univ Palacky Olomouc Czech Repub 2006; 150: 25-8.

21. Schroeder P, Haendeler J, Krutmann J. The role of near infrared radiation in photoaging of the skin. Exp Gerontol 2008; 43: 629-32.

22. Diffey BL. Solar ultraviolet radiation effects on biological systems. Phys Med Biol 1991; 36: 299-328.

23. Diffey BL. Sources and measurement of ultraviolet radiation. Methods 2002; 28: 4-13.

24. Maverakis E, Miyamura Y, Bowen MP, et al. Light, including ultraviolet. J Autoimmun 2010; 34: J247-57.

25. Anderson RR, Parrish JA. The optics of human skin. J Invest Dermatol 1981; 77: 13-9.

26. Baranoski GVG, Krishnaswamy A. An introduction to light interaction with human skin. RITA 2004; 11: 33-62.

27. Bashkatov AN, Genina EA, Tuchin VV. Optical properties of skin, cubcutaneous, and muscle tissues: a review. J Innov Opt Health Sci 2011; 4: 9-38.

28. Igarashi T, Nishino K, Nayar SK. The Appearance of Human Skin. Technical Report: CUCS-024-05. Department of Computer Science Columbia University New York, NY 10027, USA, June 2005, http://hdl.handle.net/10022/AC:P:29301

29. Nielsen KP, Zhao L, Stamnes JJ, et al. The optics of human skin: aspects important for human health. In: Proceedings from the symposium Solar Radiation and Human Health. Bjorsten $\mathrm{E}$ (ed.). The Norwegian Academy of Science and Letters, Oslo, Norway, 2008; 35-46.

30. Diffey BL, Kochevar IE. Basic principles of photobiology. In: Photodermatology. Lim HE, Honigsmann H, Hawk JIM (eds.) Informa Health Care USA Inc, New York, NY 2007; 15-27.

31. Polefka TG, Meyer TA, Agin PP, Bianchini RJ. Effects of solar radiation on the skin. J Cosmet Dermatol 2012; 11: 134-43.

32. Scientific Committee on Emerging and Newly Identified Health Risks. Light Sensitivity. European Commission, 2008; http://ec.europa.eu/health/ph risk/committees/04 scenihr/ docs/scenihr_o_019.pdf

33. Maddodi N, Jayanthy A, Setaluri V. Shining light on skin pigmentation: the darker and the brighter side of effects of UV radiation. Photochem Photobiol 2012; 88: 1075-82.

34. Robertson V, Ward A, Low J, Reed A. Electrotherapy explained. Principles and practice. Elsevier, Wroclaw, 2009.

35. Grundmann SA, Beissert S. Modern aspects of phototherapy for atopic dermatitis. J Allergy (Cairo) 2012; article ID 2012:121797; http://www.hindawi.com/journals/ja/2012/121797/

36. AAPM report no 3. Optical radiation in medicine. A survey of uses. measurement and sources. American Association of Physicists in Medicine, American Institute of Physics, 1997; 1-37, http://www.aapm.org/pubs/reports/rpt_03.pdf

37. Lee JH, Roh MR, Lee KH. Effects of infrared radiation on skin photo-aging and pigmentation. Yonsei Med J 2006; 47: 485-90.

38. Karu T. Primary and secondary mechanisms of action of visible to near-IR radiation on cells. J Photochem Photobiol B 1999; 49: 1-17.

39. Scientific Committee on Emerging and Newly Identified Health Risks. Health effects of artificial light European Commission, 2012, http://ec.europa.eu/health/scientific committees/emerging/docs/scenihr_o_035.pdf

40. Seo JY, Chung JH. Thermal aging: a new concept of skin ageing. J Dermatol Sci Suppl 2006; 2 (Suppl): S13-22.

41. Schwarz T, Halliday GM. Photoimmunology. In: Photodermatology. Lim HE, Honigsmann H, Hawk JIM (eds.). Informa Health Care Inc. New York, US 2007; 55-74.
42. Beever R. Far-infrared saunas for treatment of cardiovascular risk factors: summary of published evidence. Can Fam Physician 2009; 55: 691-6.

43. Miyata M, Chuwa T. Waon therapy for cardiovascular disease - innovative therapy for 21th century. Circ J 2010; 74: 617-21.

44. Inoue S, Takemoto M, Chishaki A, et al. Leg heating using far infra-red radiation in patients with chronic heart failure acutely improves the hemodynamics, vascular endothelial function, and oxidative stress. Intern Med 2012; 51: 2263-70.

45. Masuda A, Kihara T, Fukudome T, et al. The effects of repeated thermal therapy for two patients with chronic fatigue syndrome. J Psychosom Res 2005; 58: 383-7.

46. Matsushita K, Masuda A, Tei C. Efficacy of Waon therapy for fibromyalgia. Intern Med 2008; 47: 1473-6.

47. Oosterveld FG, Rasker JJ, Floors M, et al. Infrared sauna in patients with rheumatoid arthritis and ankylosing spondylitis. A pilot study showing good tolerance, short-term improvement of pain and stiffness, and a trend towards longterm beneficial effects. Clin Rheumatol 2009; 28: 29-34.

48. Gratton E, Toronov V, Wolf U, et al. Measurement of brain activity by near-infrared light. J Biomed Opt 2005; 10: 1-13.

49. Kateb B, Yamamoto V, Yu C, et al. Infrared thermal imaging: a review of the literature and case report. Neuroimage 2009; 47 Suppl 2: T154-62.

50. Ring EF, Ammer K. Infrared thermal imaging in medicine. Physiol Meas 2012; 33: R33-46.

51. Skoczylas A, Śliwinski P. Optoelectronic plethysmographya new technic to measure changes of chest wall volume. Pneum Alergol Pol 2007; 75: 81-7.

52. Trafidło T, Gaszyński T. NIRS - near infrared spectroscopy as a multifunctional regional tissue oxygenation monitor in the emergency and anaesthesia settings. Anestezjologia i Ratownictwo 2009; 3: 351-9.

53. Valdez-Lowe C, Ghareeb SA, Artinian NT. Pulse oximetry in adults. Am J Nurs 2009; 109: 52-9.

54. Pattison DI, Davies MJ. Actions of ultraviolet light on cellular structures. EXS 2006; 96: 131-57.

55. Garmyn M, Yarosh DB. The molecular and genetic effects of ultraviolet radiation exposure on skin cells. In: Photodermatology. Lim HE, Honigsmann H, Hawk JIM (eds.). Informa Health Care Inc. New York, US 2007; 41-54.

56. Małecka-Massalska T, Chara K, Smolen A, et al. Bioimpedance vector pattern in women with breast cancer detected by bioelectric impedance vector analysis. Preliminary observations. Ann Agric Environ Med 2012; 19: 697-700.

57. Śpiewak R. The substantial differences between photoallergic and phototoxic reactions. Ann Agric Environ Med 2012; 19: 888-9.

58. Atalay H, Erbay H, Tomatir E, et al. The use of transillumination for peripheral venous access in paediatric anaesthesia. Eur J Anaesthesiol 2005; 22: 317-8.

59. Sharma R. Use of transillumination technique is not limited to venous cannulation only. Singapore Med J 2010; 51: 904.

60. ICNIRP guidelines on limits of exposure to ultraviolet radiation of wavelengths between $180 \mathrm{~nm}$ and $400 \mathrm{~nm}$ (incoherent optical radiation). Health Physic 2004; 87: 171-86.

61. Ledo E, Ledo A. Phototherapy, photochemotherapy, and photodynamic therapy: unapproved uses or indications. Clin Dermatol 2000; 18: 77-6.

62. Sygit K, Kołłątaj W, Goździewska M, et al. Lifestyle as an important factor in control of overweight and obesity among schoolchildren from the rural environment. Ann Agric Environ Med 2012; 19: 557-61. 